\title{
“EL GUARO BLANCO ES UN ALIMENTO...”: REVISITANDO TEXTOS DE LA POLÉMICA NACIONALISTA EN LITERATURA
}

\author{
Irene González Muñoz
}

\section{(c) $(7) \Theta$}

Doi: https://doi.org/10.15517/rfl.v44i2.34667

URL: https://revistas.ucr.ac.cr/index.php/filyling 



\title{
"EL GUARO BLANCO ES UN ALIMENTO....": REVISITANDO TEXTOS DE LA POLÉMICA NACIONALISTA EN LITERATURA
}

\author{
“EL GUARO BLANCO ES UN ALIMENTO...”: REVISITING TEXTS \\ FROM NATIONALIST POLEMIC IN LITERATURE
}

Irene González Muñoz

\begin{abstract}
RESUMEN
Todo texto literario es tributario de otro mucho más amplio: la cultura, esto justifica el abordaje de las representaciones literarias de la comida y de los alimentos, pues según lo afirma D. Bunn, desde la perspectiva sociológica, la ingesta de alimentos (líquidos o sólidos) no responde exclusivamente a una necesidad vital, sino que también implica una serie de aspectos socioculturales identificables en el texto literario. Además, siguiendo los planteamientos de M. Calvillo Jurado, la incorporación de alimentos en el discurso literario también da cuenta de la conformación de personajes-tipo. En este sentido, la siguiente propuesta analiza cómo se representa en la cuentística de Ricardo Fernández Guardia, correspondiente a la polémica nacionalista en literatura, la relación que se establece entre el consumo de licor y la identidad del concho costarricense.

Palabras clave: literatura costarricense, cuento, polémica nacionalista en literatura, Ricardo Fernández Guardia, crítica.
\end{abstract}

\begin{abstract}
Every literary text is tributary of something broader: culture. This justifies the approach of literary representations of food, since according to D. Bunn, from a sociological perspective, the intake of food (liquid or solid) doesn't respond exclusively to a vital necessity but also implies a number of sociocultural aspects that can be identified in literary texts. Furthermore, following the approach of M. Calvillo Jurado, the incorporation of food in literary discourse also accounts for the conformation of character-types. In this sense, the following text analyzes how the storytelling of Ricardo Fernández Guardia, which corresponds to nationalist polemic in literature, represents the association between the consumption of licor and the identity of the concho costarricense.

Key words: Costa Rica literature, story, nationalist polemic in literature, Ricardo Fernández Guardia, literary criticism.
\end{abstract}

Según se plantea en la Sociocrítica, todo texto literario es tributario de otro mucho más amplio: la cultura, depositaria de todos los saberes posibles. Se propone así un primer argumento que fundamenta la pertinencia del estudio sobre las representaciones literarias de la comida y de los alimentos. El segundo argumento se plantea desde la perspectiva sociológica

M.L. Irene González Muñoz. Universidad de Costa Rica. Profesora de la Escuela de Filología, Lingüística y Literatura. Costa Rica.

Correo electrónico: irenego123@hotmail.com

Recepción: 30- 06- 2017

Aceptación: 06- 09- 2017 
de que la ingesta de alimentos, ya sean líquidos o sólidos, no responde exclusivamente a una necesidad vital del ser humano, sino que también implica una serie de aspectos socioculturales, tal y como lo indica Daniela Bunn al afirmar que "el acto alimenticio no es sólo biológico, es también representación de ciertos valores culturales. La simbología de la comida y del acto de comer puede traernos la comprensión de valores culturales o históricos" (Bunn, 2009, párr. 2). Idea que, por demás, nos lleva a una serie de cuestionamientos, por ejemplo, por qué razones los alimentos llegan a ser tema central en un texto determinado, qué función tienen en las historias en las que se incluyen y cómo se construyen esas funciones.

En este sentido, en el presente estudio se analiza cómo se representa en algunos de los cuentos de Ricardo Fernández Guardia la relación que se establece entre el consumo del licor y la identidad del concho costarricense, pues siguiendo a Miguel Calvillo Jurado, en Introducción a las relaciones entre cocina y literatura (s.f.), en el texto literario la alimentación es una típica fuente caracterizadora de los personajes. Así, a través de ella se posibilita la identificación de su nivel social (ricos o pobres) y cultural (modernos o tradicionales).

En otras palabras, la alimentación, al estar unida a la historia del personaje, se convierte en un atributo más de este, al punto de que la relación comida/personaje ha dado origen a personajes-tipo como el glotón, el gorrón y, modernamente, el anoréxico y el bulímico (Calvillo Jurado, s.f.).

En otras ocasiones, al considerarse como uno de los placeres humanos, la alimentación se convierte en protagonista de la historia como ocurre en los relatos de banquetes y de atiborramientos. Este protagonismo de la comida se suele asociar con la mitigación de dolores y de sufrimientos de los personajes, ya que los ayuda a superar etapas difíciles, sea al satisfacer una necesidad del cuerpo, como el hambre, o para transformar una ocasión determinada en un acto de sociabilidad.

Es extensa la lista de textos literarios en los que la comida tiene un marcado protagonismo. Solo para referir algunos ejemplos podemos citar el texto clásico El Satiricón de Petronio, en el cual la comida cobra un protagonismo absoluto en el banquete que Trimalción, personaje liberto que a través del trabajo duro y la perseverancia ha alcanzado poder y riqueza, y que probablemente por haber sido víctima de la escasez en su vida de esclavo, una vez superada esta etapa, no escatima en lo más mínimo para ofrecer a sus invitados una cena opípara en la que abundan en exceso no solo la comida y la bebida, sino también los desmanes de los convidados.

Otro ejemplo en el que se establece cierto protagonismo de los alimentos nos lo brinda F. Rabelais con sus personajes Gargantúa y Pantagruel, quienes se caracterizan por un apetito voraz que da pie a la relación de situaciones cómicas y grotescas, las cuales contribuyen con el discurso subversivo y disidente de esta obra de Rabelais.

Ahora bien, el propósito no es referir una lista de producciones literarias en las que los alimentos tienen un rol central, sino más bien analizar, concretamente, qué función desempeña la inclusión y el tratamiento de las bebidas alcohólicas en varios cuentos del escritor costarricense Ricardo Fernández Guardia, esto porque, como ya se ha indicado, la inclusión de alimentos en un texto literario no es fortuita y está lejos de ser una inclusión meramente arbitraria e inocente. Cabe recordar en este sentido que el signo en el texto literario no es arbitrario, sino más bien todo lo contrario, pues se trata de un signo altamente motivado; es decir, citando a Lotman (1996), la literatura en cuanto estructura modelizante secundaria genera que los signos que la conforman adquieran un valor significativo y un sentido específico dentro del texto. Afirma, además, este mismo autor que "no existen por sí solos en forma 
aislada sistemas precisos y funcionalmente unívocos que funcionan [sic.] realmente" (Lotman, 1996, p. 22), sino que el sentido que se otorga al texto depende básicamente de la red de relaciones entre los diversos sistemas semióticos involucrados en el proceso de significación.

Otra consideración pertinente en este punto es la propuesta del formalista ruso Boris Tomashevsky, en su ensayo "Temática" (1978), en el que se refiere a la inclusión de los motivos (unidades mínimas del material temático) a partir, precisamente, del procedimiento de motivación, el cual consiste en la estrategia de vinculación de los motivos en la obra literaria. Según Tomashevsky, hay tres tipos de vinculación; a saber, la realista, la artística y, la que nos interesa en este caso, la motivación por la composición, la cual se basa en la economía y en la utilidad de los motivos, en otras palabras, todo motivo que se incluya en la historia debe ser aprovechado y debe tener una influencia en el desarrollo de la fábula. De acuerdo con esta propuesta, todo objeto o acontecimiento que se incluya en la historia narrada debe tener un sentido, contribuir con la coherencia interna del texto. Así, si al inicio de una narración se menciona que hay un clavo en la pared, ese clavo debe ser determinante en algún momento de la historia, pues el hecho de señalar su ubicación implica, necesariamente, que tiene una función específica.

Una vez aclarados estos aspectos teóricos, corresponde referir algunos aspectos fundamentales de los textos de Fernández Guardia que se consideran en esta propuesta de lectura: "Tapaligüi”, de la colección de cuentos Hojarasca (1894), "Un Héroe” y "Un santo milagroso", de Cuentos Ticos (1901). Ambas publicaciones se enmarcan dentro la conocida polémica nacionalista en literatura que protagonizaron don Ricardo Fernández Guardia y don Carlos Gagini, y cuyo punto de partida fue, de hecho, la publicación de Hojarasca.

La discusión original de la polémica se centró, en una primera etapa, en los asuntos que según Gagini debían desarrollarse en la naciente literatura costarricense y que estaban ausentes en los cuentos de Fernández Guardia. Defendía don Carlos, ante todo, los temas y los personajes nacionales, pues la literatura nacional debía dar cuenta del entorno costarricense y no centrarse en temas foráneos, tendencia muy marcada en Hojarasca.

En una segunda etapa, que da inicio en el año 1900 con la publicación de El Moto, de Joaquín García Monge, la polémica se revitaliza, en esta oportunidad a los asuntos nacionales se suma la discusión en torno a qué variante del español debía utilizarse. Abogaban los nacionalistas, encabezados por Gagini, en utilizar la variante lingüística del español popular costarricense, mientras que los modernistas, liderados por Fernández Guardia, defendían la variante estándar del español.

La discusión sobre estos aspectos se llevó a cabo por medio de cartas que se publicaron en los diarios de la época y fue una discusión que se caracterizó por un tono fuerte. Por ejemplo, en cuanto a la discusión sobre la variante del español por utilizar, Fernández Guardia acusa a García Monge de haber escrito El Moto con el Diccionario de costarriqueñismos de Carlos Gagini.

Otro de los argumentos fuertes de esta discusión tuvo que ver con la afirmación de Gagini de que era necesario escribir sobre "los mil sujetos nacionales que pudieran dar motivo a otras obras literarias interesantísimas y llenas de novedad para los extranjeros" (Gagini, 1995, p. 20), a lo cual don Ricardo responde que de una india de Pacaca solo podía salir otra india de Pacaca, no una Diana de Houdon o una Venus de Milo, personajes que podían construirse si se consideraba a una 'parisiense graciosa y delicada' y a 'una griega de la antigüedad', respectivamente, razón por la cual el sujeto nacional no podía ser considerado como material literario (Fernández Guardia, 1995). 
En fin, los diversos acercamientos y estudios que se han hecho a la polémica evidencian que fue a partir de este intercambio epistolar entre los denominados nacionalistas y modernistas que se establecieron los parámetros de la literatura nacional, de tal manera que se establece el realismo costumbrista como modelo de escritura que se centra en el personaje del concho blanco de la Meseta Central y en la variante popular del español de Costa Rica.

Precisamente, estos parámetros de escritura contribuyen con la conformación del discurso del imaginario de la identidad nacional, que fundamenta la construcción del costarricense idealizado y que se caracteriza por ser un campesino blanco, trabajador ('labriego sencillo'), pacífico ('buen cristiano'), humilde y auténtico, representación esencial del costarricense.

Curiosamente, a pesar de las acusaciones de Gagini hacia don Ricardo, en Hojarasca se hallan dos cuentos que no se ajustan al resto de los que conforman esta publicación, se trata de “¿Neurosis?” y de “Tapaligüii”. El primero, sí refiere un asunto o tema nacional y contribuye con la reproducción del imaginario identitario; trata sobre Juan Zamora un joven costarricense que es enviado a estudiar medicina a París, pero pronto es seducido por la vida bohemia, el arte y la música, por lo cual abandona sus estudios de medicina. Ante este panorama, su padre lo hace regresar a Costa Rica a trabajar en la hacienda cafetalera familiar. En esta hacienda lo localiza su amigo Ramón quien se sorprende al ver a su amigo convertido en un campesino al que se refiere de la siguiente forma

Al pronto no le hubiera conocido; no era el mismo Juan Zamora, aquel mozo esbelto y lleno de arrogancia que tan buena figura hacía en el bulevar San Miguel; el hombre que tenía delante era un campesino tosco y mal trajeado. (Fernández Guardia, 2004b, p. 70)

No obstante esta impresión de Ramón, Juan Zamora confiesa ser feliz con su trabajo en la hacienda, de hecho, tiene proyectos para mejorar la producción de café y sostiene que su vida en la finca es auténtica; es decir, consecuente con su condición de origen y, por lo tanto, "verdadera". Esta idea se colige de la forma en que Zamora describe la agitada y tumultuosa vida en la ciudad de París llena de tiendas, de restaurantes, de cafés, del ruido del tranvía y llena también de vida y de inteligencia, en contraste con el ambiente apacible de la finca, el cual considera auténtico a pesar del aislamiento, tal y como se lo hace ver a Ramón cuando le dice: "Si estuviéramos allá... esta taza de café la estaríamos tomando en casa Vachette y de fijo que no estaría tan buena, porque la habrían adulterado con chicoria” (Fernández Guardia, 2004b, p. 75).

No resulta extraño que se refiera a la autenticidad de su vida en la hacienda a partir de una taza verdadera y no adulterada de café, baste recordar lo que este cultivo representó para el desarrollo social y económico en Costa Rica.

Ya antes, en otro pasaje del cuento, se manifiesta la autenticidad de la vida en el espacio nacional, justamente cuando los amigos se preparan para almorzar y en este caso es Ramón quien dice lo siguiente en relación con los alimentos

\footnotetext{
Apetito para nosotros excelente, la hubieran despreciado muchos de seguro, por ser rigurosamente compuesta de guisos nacionales: la carne asada, los negros frijoles relucientes, el dorado plátano frito, el arroz blanquísimo y las tortillas de maíz bien tostadas. Juan sacó de una alacena una deliciosa botella de burdeos. "Es el único resabio de gourmet que me queda -exclamó alegremente llenándome la copa-. El vino, Ramoncito, es amigo del hombre. (Fernández Guardia, 2004b, p. 72)
}

Como vemos, los platillos dispuestos para el almuerzo son, en efecto, los típicos de la gastronomía costarricense, diríamos que se trata del tradicional casado. Nótese que a pesar de la mencionada excelencia de este almuerzo, según lo indican las palabras de Ramón, no se puede calificar de gourmet, sobre todo cuando indica que muchos lo despreciarían por estar compuesto 
de guisos nacionales. Lo anterior se refuerza con la elección de la bebida para acompañar esta comida, un vino de burdeos "único resabio de gourmet". Una vez más, se evidencia la ambigüedad en la que se mueven los personajes de esta historia, pues aunque por una parte alaban la autenticidad de la vida en Costa Rica, por otra, siguen añorando su vida en Europa.

Ahora bien, y siguiendo con el tema en cuestión sobre las bebidas alcohólicas que se incluyen en estos cuentos de Hojarasca, es sintomático que cada vez que se menciona una, se trata de algún licor 'exótico', no nacional. Solo para ofrecer dos ejemplos, en "El cuarto de hora", cuento en el que un grupo de personajes se dedican a comentar, precisamente, sobre 'el cuarto de hora', forma eufemística para referir las infidelidades de las mujeres casadas, uno de los personajes, el general Pérez, se dispone a narrar una historia sobre un supuesto amigo suyo en estos asuntos, y relata a sus oyentes que la aventura se inició con un paseo por el estero, en Puntarenas, y que mientras disfrutaban de la música de la marimba, una vez que saltaron a tierra "comenzaron a estallar los corchos de champaña" (Fernández Guardia, 2004b, p. 5). Más aún, este personaje indica que la dama en cuestión "parecía mucho más comunicativa que de costumbre, haciendo mil mohines cada vez que mi amigo se empeñaba en hacerla beber otra copa de champaña" (Fernández Guardia, 2004b, p. 6).

En "Lolita", historia que se desarrolla en Madrid, un joven se ve enredado en la telaraña de una femme fatale, y es el mismo protagonista quien expresa que se encontraba en un ambiente "en que no escaseaban los buenos palmitos ni las botellas de champaña" (Fernández Guardia, 2004b, p. 16).

Son precisamente aspectos como estos los que Carlos Gagini critica de Hojarasca, historias de salón de una clase social alta que se ambientan en su mayoría fuera del espacio de lo nacional y la mostración de algunas prácticas sociales no muy 'nacionales', como se puede apreciar en lo referente al consumo de licores.

Sin embargo, sí se encuentra en esta publicación un cuento en el que se habla de una bebida alcohólica autóctona, la chicha, y es en "Tapaligüi”. En este cuento se narra la historia de un triángulo amoroso entre Nambi, cacique de Nicoya, Miri y Tapaligüi, hijo del cacique de Chira, enemigo de Nambi. Aunque la historia de este triángulo es el meollo de la fábula, es imposible dejar de lado el contexto en el que se nos presenta la historia de estos personajes y que se nos ofrece desde el primer párrafo. Todo inicia con una fiesta religiosa y tradicional en el pueblo de Nicoya, la instancia narrativa nos dice que la gran plaza del pueblo está repleta de un gentío impaciente

porque llegase la hora en que comenzarían los bailes y ritos, todo lo cual vendría a parar a la postre en una inmensa borrachera, porque bien sabido es que el embriagarse ha sido en todo tiempo el placer favorito de los indios (Fernández Guardia, 2004b, p. 53)

Como vemos, esta función ideológica de la voz narrativa al indicar que es 'bien sabido' que el placer de los indios es embriagarse, desvirtúa el carácter religioso de la festividad y, por ende, el del consumo de la chicha, bebida de maíz sagrada para la cultura indígena de esa zona. De tal forma que se plantea el juicio de que 'los indios' tienen un comportamiento licencioso y criticable. Este juicio se va consolidando cada vez más negativamente conforme se va describiendo el ambiente de la festividad, pues con la embriaguez las danzas reflejan otro aspecto degradante de la celebración: "A poco rato aparecieron muchas mujeres trayendo vasijas llenas de una chicha de maíz muy fuerte. Repartiéronse por entre los danzantes, los cuales sólo paraban un minuto para beber y luego seguían agitándose con movimientos epilépticos" (Fernández Guardia, 2004b, p. 54). 
Más adelante indica que la fiesta se extiende a lo largo del día sin miras de finalizar, más aun, al llegar la noche "ya había degenerado en asquerosa orgía, siendo la embriaguez general" (Fernández Guardia, 2004b, p. 55). La festividad termina cuando el propio cacique Nambi es el último en caer, literalmente, mientras que por todos "lados yacían los actores de la fiesta en las posturas más estrambóticas; algunos gemían y se agitaban, sin duda víctimas de horribles pesadillas; otros roncaban como tubos de órgano; los más parecían muertos" (Fernández Guardia, 2004b, p. 56).

Obviamente, esta percepción negativa de la fiesta religiosa se ve determinada en parte por la visión hegemónica desde la cual se construye la historia, pues se representa al 'indio' (según lo denomina la propia instancia narrativa) como el otro, y este discurso sobre el otro se refuerza con la ingesta de la chicha, causa final de los mencionados desmanes de los personajes de esta historia. Un dato importante y pertinente para explicar esta representación de los indígenas en "Tapaligüi”" y la ingesta de la chicha, así como de sus efectos, nos lo brinda don Carlos Gagini, quien en su Diccionario de Costarriqueñismos define chicha de la siguiente forma: "Chicha.-Berrinche, enojo, mal humor, rabieta; sin duda por los efectos de esa bebida alcohólica. Se emplea la palabra en el modismo "estar de chicha"” (Gagini, 1919, p. 111). Precisamente la expresión 'estar de chicha' implica una alteración del ánimo que podría ir desde el mal humor y el enfado hasta el comportamiento irracional de una persona, con lo cual se refrenda el estado alterado de los 'indios' durante la mencionada celebración.

Finalmente, la historia del triángulo amoroso en este cuento se resuelve con el sacrificio de Miri en la gran fiesta del sol y con el inminente enfrentamiento entre Nambi y Tapaligüi, pero todo queda en cierto suspenso cuando en medio de esta situación se escucha un fuerte trueno y se relata el final de la historia

\footnotetext{
Allá en la mar, balanceándose suavemente sobre las aguas, estaba un barco monstruoso; en su popa flameaba el pendón soberbio de Castilla y por una de sus bandas humeaba aún la boca de un cañón. Espesos nubarrones cubrieron el cielo y apagaron su brillo.

El culto del sol había muerto. Comenzaba el del Crucificado. (Fernández Guardia, 2004b, pp. 64-65)
}

Es indudable, después de leer este cuento, concluir que nos ofrece una visión negativa no solo de los indígenas, sino también del licor sagrado ya que se asevera que su consumo solo genera situaciones anómalas, esto desde la perspectiva de la instancia narrativa, la cual constantemente hace uso de su función ideológica al introducir juicios de valor sobre los indígenas y las costumbres que relata, por ejemplo, cuando indica que "rompieron todos a bailar, cantando y haciendo muecas y contorsiones extravagantes" (Fernández Guardia, 2004b, p. 54). Es posible, entonces, coincidir con las propuestas de Todorov, en La conquista de América. El problema del otro, de que los indios no son concebidos como "sujetos en sentido pleno, es decir, sujetos comparables con el yo que los concibe" (2007, p. 142). En otras palabras, en "Tapaligüi" se reproduce el discurso hegemónico del conquistador en relación con el conquistado en los mismos términos en los que se plantea en las crónicas de Indias, pues no se reconoce al otro (el 'indio') en tanto sujeto, sino que se habla de él (Todorov, 2007), pero en este caso no se habla bien de él.

Tratamiento muy diferente de las bebidas alcohólicas se hace en "Un héroe" y "Un santo milagroso", de Cuentos Ticos, publicado en 1901. Para empezar ya no se trata de bebidas 'exóticas' o 'ajenas' a lo costarricense, sino del aguardiente o guaro, licor que se produce a partir de la caña de azúcar. Se puede afirmar sin lugar a dudas que los asuntos 
o motivos de los cuentos que conforman esta colección son de índole nacional, lo cual se establece desde su título, Cuentos ticos.

Las dos historias seleccionadas giran, sustancialmente, en torno al consumo del guaro de contrabando o guaro blanco y sus efectos, pero en este caso la ingesta de este licor y sus consecuencias distan, en gran medida, de las que se establecieron anteriormente en relación con la chicha.

En "Un héroe" conocemos la vida de Joaquín García, un zapatero alcohólico de la ciudad de Cartago que solía ser el blanco de las travesuras de los chiquillos y al que todos conocían "con el sugestivo apodo de Cususa" (Fernández Guardia, 2004a, p. 29), término con el cual se llamaba al aguardiente. Sobre esto dice don Carlos Gagini en su diccionario que cususa es el "aguardiente de caña, particularmente el de fabricación clandestina" (Gagini, 1919, p. 106).

Cususa no todo el tiempo se la pasaba alcoholizado, tenía sus periodos de sobriedad en los que se dedicaba a trabajar con ahínco en su zapatería, atendiendo a su numerosa clientela pues era un gran artesano. Sin embargo, también tenía sus periodos de embriaguez en los que hacía gala de una alegría sin igual

El distintivo del carácter del zapatero era la alegría, un alegría loca, irresistiblemente comunicativa. Cuando al pasar
por alguna taberna se oían gritos, risas, música y bailoteo, no había que preguntar la causa. Sólo Cususa era capaz de
convertir en jolgorio la díscola tristeza de los bebedores de aguardiente. (Fernández Guardia, 2004a, p. 29)

Estos periodos solían darse generalmente durante la Semana Santa, pues se entregaba de lleno a la bebida después de la procesión del Domingo de Ramos y así continuaba hasta la procesión del Señor del Triunfo, y también durante las celebraciones patrias cuando era muy común verlo bailar al compás de un paso doble detrás de las tropas gritando "Viva Costa Rica", pues era ante todo un patriota.

Pese a su afición al consumo de licor, Cususa no era un hombre pendenciero, más bien se caracterizaba por ser conciliador en situaciones de violencia y, más aún, por detener las peleas haciendo gala de su valentía y de su fuerza física. Como diríamos en el lenguaje coloquial, a Cususa la ingesta de licor no le causaba 'mal guaro', sino todo lo contrario. Gagini en su ya citada obra dice lo siguiente: "Del que se enfurece o pone de mal humor cuando toma copas, decimos familiarmente que "tiene mal guaro"” (1919, p. 151).

En una ocasión, mientras Cususa duerme su borrachera en la calle, unos niños de Cartago le embadurnan la cara, pero es defendido por el capitán Ramírez. Este excombatiente de la Campaña del 56 y superior de Cususa, advierte a los niños que esa no es la forma de tratar a un héroe como Joaquín, pues nuestro personaje también es excombatiente de las batallas de Santa Rosa y de Rivas, así como de la cruenta batalla naval en la que participó el bergantín de guerra Once de Abril, el cual fue hundido por el Granada, nave de los filibusteros, y Cususa participó en todas ellas, a pesar de haber sido dispensado, ya que era el único sostén de su madre.

Es de hecho en esta batalla naval en la que Joaquín demostró su temple al salvar a varios de sus compañeros de morir ahogados al llevarlos al Granada. En esta labor de rescate él decide no rendirse para no pasar por la vergüenza de ser prisionero del enemigo, por lo que escoge la posibilidad de morir ahogado antes que abordar el Granada. Sin embargo, según lo narra el capitán Ramírez, Joaquín pudo asirse a un barril y llegar a la costa donde

Agonizante fue hallado en la playa por unas buenas gentes que se propusieron volverlo a la vida con enérgicas fricciones y tragos de aguardiente que tenían que hacerle beber a la fuerza, porque hasta aquella ocasión había sido sobrio en extremo. Pero desde entonces ya no lo fue tanto, y no es otro el origen de su intemperancia. (Fernández Guardia, 2004a, p. 40) 
Nótese cómo el capitán denomina el gusto de Cususa por el aguardiente como 'intemperancia'; es decir, como falta de moderación o pérdida de su temple, a la vez que justifica a partir de un posible trauma de guerra su afición por el aguardiente, con el cual, además, revive.

Evidentemente, como se puede comprobar, Cususa, a pesar de su 'sugestivo' apodo, es el sujeto ideal del imaginario de la identidad nacional, ese al que se canta en el Himno Nacional, alegre, trabajador, patriota, no pendenciero, pero dispuesto a sacar la casta cuando es necesario, en suma, un héroe, de ahí que tenga licencia para el consumo del 'guaro blanco' que incluso le devolvió la vida. Además, recordemos que a él no le da 'mal guaro'.

En "Un santo milagroso", se nos presenta otra historia en la que el aguardiente también es un motivo temático importante. Se trata de la problemática que viven algunas comunidades de Alajuela en las que las festividades como rosarios y velas solían terminar en escándalos y pendencias, en algunos casos incluso había muertos, lo curioso es que en todas había un elemento en común, la presencia particular de la imagen de un santo, San Jerónimo, sobre esta imagen reza el texto

\begin{abstract}
A primera vista la imagen no presentaba ninguna particularidad saliente. Era una escultura tosca de madera coloreada, de poco más de un metro de altura. El santo, vestido con hábito de raso galoneado de plata, estaba lejos de tener el aspecto de un asceta; antes parecía uno de esos frailes barrigudos e incontinentes que han popularizado las cromolitografías catalanas. Pero este detalle en que sólo habían reparado algunos criticones y mal intencionados de la ciudad de Alajuela, no afectaba en nada la devoción de sus adoradores, que no se hartaban de festejarlo ni de besarle los pies. (Fernández Guardia, 2004a, p. 44)
\end{abstract}

Resulta interesante que en la descripción de esta imagen el narrador apunte a ese aspecto nada austero del santo al señalar que es 'barrigudo' e 'incontinente', indicios inequívocos de lo que sucederá después. Según lo plantea la instancia narrativa, lo que menos preocupaba a las autoridades era la extraña y desmedida devoción a la imagen, pues asumían este 'fanatismo grosero' como propio de la gente del campo. Lo que realmente inquietaba era el hecho corroborado de que festejo en que estuviera el santo, terminaba a 'machetazos y puñaladas', razón por la cual el gobernador de Alajuela dio la orden de capturarlo; sin embargo, el santo siempre lograba escapar. Ante la desesperación del gobernador, el cabo del resguardo de Hacienda, Pedro Villalta se compromete a capturar definitivamente la imagen y le dice al gobernador: "-No tenga usted cuidado, señor; yo me encargo de traerle el santito ese" (Fernández Guardia, 2004a, p. 45). Para cumplir con esta tarea, el cabo Villalta, que era 'viejo' y 'muy matrero', urde engañar a la gente de Alajuela, anunciando que tanto él como sus subalternos deben ir a Puntarenas tras unos contrabandistas, así los espías de estos indicarían que los del resguardo no estaban cerca y bajarían la vigilancia en las sacas (fábrica de aguardiente clandestino). El objetivo de Villalta era incautar la saca de los hermanos Arias, contrabandistas peligrosos y pendencieros.

Una vez que han despistado a los espías deciden volver a Alajuela por otro camino. Cuando ya van de vuelta, se encuentran con un hombre que les pregunta si van a la vela de ñor Carvajal, la cual promete estar muy bonita. Villalta comprende al instante que es una oportunidad que no puede dejar pasar y, en efecto, se dirige a la vela.

Entretanto, la vela ya se celebraba, había música y baile, así como comida; a saber, bizcochos, empanadas, cigarros y botellas de guaro mixturado para las mujeres. En un momento determinado

Empezó la extraña ceremonia. "Señores -dijo el dueño de la casa- adoremos al santo". Uniendo el gesto a la palabra, se acercó a la imagen, y, postrado ante ella, le besó largamente el pie. Todos los hombres, uno tras otro, 
hicieron lo mismo. Las mujeres fueron mucho menos entusiastas y sólo hubo cuatro o cinco que besaban el pie del bienaventurado. (Fernández Guardia, 2004a, p. 50)

De pronto llega a la vela uno de los Arias, José, con la intención de robarse a una de las mujeres que se encuentran en la celebración, por lo que se inicia una pelea entre el novio de la muchacha y José Arias, en ese momento llegan los del resguardo e intentan detener al temido contrabandista, pero este, ágilmente, levanta en peso la imagen de San Jerónimo, la lanza contra los guardas y logra huir. Villalta le dice a sus hombres que no lo persigan, que al menos habían atrapado al santo. Ante esta captura, la instancia narrativa expresa, con sorpresa y humor, lo siguiente

¡Y qué pájaro tan gordo habían atrapado los guardas! Nada menos que el inhaliable [sic.] san Jerónimo que yacía a la vera del pobre Juan Rodríguez uno de los guardas, al cual sus compañeros ayudaban a levantarse. El cabo se quedó absorto examinando al santo. De pronto dio un grito de alegría:

-¡Ya pareció el peine! ¡Ya pareció el peine! -exclamaba a la vez que hacía mover un ingenioso mecanismo, disimulado en un dedo del pie izquierdo de la imagen y por el cual salía un chorrito de aguardiente clandestino. ¡San Jerónimo sangraba guaro! (Fernández Guardia, 2004a, pp. 53-54)

Descubierto el milagro, el mismo cabo Villalta dice a sus subalternos que adoren al santo, “y para dar el ejemplo besó con devoción el pie del bienaventurado" (Fernández Guardia, 2004a, p. 54). Finalmente, la noche siguiente el gobernador celebraba la captura del santo, en la prisión, junto con sus amigos y con el detenido San Jerónimo.

Cabe señalar que la captura del San Jerónimo, distrajo a los guardas del resguardo de dar con los verdaderos causantes de la situación ilícita. A esto contribuye, en primera instancia, lo jocoso de las circunstancias en que se desarrolla la fábula y en el tono humorístico que alcanza hacia el final, cuando se conoce el 'milagro', y no el delito, lo que a la postre evita la censura en cuanto al consumo de bebidas alcohólicas y a sus consecuencias negativas durante las celebraciones populares; es decir, los desórdenes públicos, los heridos e, incluso, las muertes que se provocaron. Más aún, no se condena en esta historia, el hecho de que se trata de guaro de contrabando, ${ }^{1}$ pues en el momento en que Villalta, el cabo del resguardo, cuya tarea es acabar con el problema del contrabando, decide 'adorar' al santo, no hay posibilidad alguna de censura. Y, para cerrar con broche de oro, el mismo gobernador convida a sus amigos a la prisión para celebrar, como se dice popularmente, 'chupando guaro'.

Recapitulando, un recorrido por estos cuentos de Ricardo Fernández Guardia nos brinda diversas representaciones de las bebidas alcohólicas y, a la vez, nos permite plantear algunas conclusiones.

En primera instancia, a partir del tipo de licor que se incluye en cada una de las historias, llegamos a una conclusión general; a saber, la ingesta de licor establece datos socioculturales. Esto se evidencia en la mayoría de los cuentos de Hojarasca, en los cuales los licores que se consumen en las reuniones sociales que se relatan van del vino blanco, a la champaña y al vino de burdeos, este último incluso para acompañar el emblemático plato típico, el casado, en “¿Neurosis?”. En este sentido, es claro que estos licores no nacionales se asocian con las fiestas de salón de una clase social alta, cuyas costumbres se asocian con parámetros europeos.

En cuanto a los cuentos "Un héroe" y "Un santo milagroso", de Cuentos Ticos, el consumo de aguardiente se relaciona con las clases populares y, nótese que no se trata de cualquier aguardiente sino de cususa o guaro de contrabando, cuya fabricación es clandestina, pero en estas historias su ingesta no se censura, todo lo contrario, nos atreveríamos a decir que se promueve, sobre todo si recordamos que fue esta bebida, gracias a sus cualidades curativas, 
la que revivió a Cususa, y que en el caso de este héroe antes que causarle problemas, ya que Cususa no 'tiene mal guaro', le ayuda a exaltar las cualidades positivas del sujeto nacional/ concho sobre el que se construye el imaginario de la identidad nacional.

En una segunda instancia, se plantea una diferencia étnica y cultural muy marcada entre el consumo de la chicha y el consumo del aguardiente o 'guaro blanco', como se le llama en el Himno al Guaro, pues en el caso de "Tapaliguii", como se estableció antes, a pesar de que el asunto central del cuento pareciera ser el triángulo sentimental entre los personajes indígenas este hecho se traduce en un (pre)texto, pues ya desde el íncipit se da una dilación para nada arbitraria, al describirse detalladamente la fiesta religiosa y el consumo de la chicha, bebida que genera actitudes lascivas y grotescas por parte de los 'indios', según lo expone la instancia narrativa. En este sentido, la relación de la fiesta favorece, según lo propone Tomshevsky, la inserción de la bebida alcohólica, la chicha, como motivo que cumple una función ideológica para establecer una marcada diferencia cultural, pues se implica una distinción chicha/ aguardiente, que se podría hacer extensiva a la distinción 'indio'/blanco, que se evidencia en el discurso racista del cuento, y que se refrenda con el final de la historia cuando al referirse a la llegada de los españoles se dice que: "El culto del sol había muerto. Comenzaba el del Crucificado" (Fernández Guardia, 2004b, p. 65).

En resumen, podríamos afirmar que la utilización de las bebidas alcohólicas como unidad mínima del material temático en estas historias contribuye no solo como mecanismo que estructuralmente sustenta la coherencia de las tramas en estas narraciones, sino que también contribuye con las representaciones ideológicas en las que se sustenta el imaginario de la identidad nacional. De lo anterior se colige que cada personaje, ya sea Juan Zamora, Cususa o Nambi, consume, acorde con sus circunstancias, la bebida alcohólica adecuada a su 'naturaleza', a su condición, sea esta social o étnica, tal como lo plantea Daniela Bunn (2009), y a su vez esto implica la construcción de personajes-tipo. Por una parte, se representa al refinado y eurocéntrico oligarca y al festivo y popular concho, los cuales se identificarían con la construcción del imaginario nacional en cuanto a la identidad del costarricense y, por otra, se representa al insaciable y orgiástico ‘indio', el cual se asume como el otro interno. Así, a partir de la chicha y del aguardiente se reproduce la visión de mundo de un sujeto cultural que concibe sus orígenes estrictamente europeos, en oposición al origen del 'indio', por eso no es errado afirmar que en esta cuentística, de la polémica nacionalista en literatura, se reproduce el mismo discurso hegemónico de los conquistadores en las Crónicas de Indias, discurso en el que se plantea un antagonismo entre el yo y ese otro, el 'indio', que no llega a ser sujeto y, por lo tanto, no es comparable con el yo. Este antagonismo se refuerza más aún con las expresiones populares que don Carlos Gagini define en su Diccionario de costarriqueñismos y con las que se suele calificar el efecto de la chicha y del aguardiente en quienes las consumen, pues este caso que nos ocupa no es lo mismo "estar de chicha" que no "tener mal guaro". Por esto, baste con recordar quién es Cususa, el héroe, y cuáles son las calidades que se le adjudican

Todos conocíamos con el sugestivo apodo de Cususa a un pobre zapatero de ojos azules pequeñitos, perdidos en la espesura hirsuta de sus cejas grises...

El distintivo del carácter del zapatero era la alegría, una alegría loca, irresistiblemente comunicativa. Cuando al pasar por alguna taberna se oían gritos, risas, música y bailoteo, no había que preguntar la causa. Sólo Cususa era capaz de convertir en jolgorio la díscola tristeza de los bebedores de aguardiente. (Fernández Guardia, 2004a, p. 29) 


\section{Notas}

1. Según lo explica Jorge Sanabria Marchena (2015), desde mediados del siglo XIX se establece por ley en Costa Rica el monopolio de la Fábrica Nacional de Licores, pues con la fundación de la Fábrica Nacional de Licores (FANAL) en setiembre de 1850, se intensificó la demanda de dulce y panela provenientes de la caña, con el fin de confeccionar alcohol, con lo que la actividad recibió un importante aliciente para su producción; además, el Estado se benefició ampliamente de este monopolio, pues como se puede documentar con certeza, entre 1850 y 1900, gran parte de sus ingresos provenían de los impuestos al aguardiente.

El establecimiento del monopolio estatal de licores obedeció a diversas razones, entre ellas destacan salvaguardar la salud de la población, amenazada y dañada por el consumo de bebidas alcohólicas de alta toxicidad y que era promovida por la empresa privada, así como fomentar y ayudar a la empresa cañera, fuente de materia prima para la producción de alcohol y sus derivados; además, de proporcionar ingresos al Fisco, mediante los impuestos con que se gravarían las bebidas alcohólicas y eliminar la fuga de divisas al no tener que importar licores.

\section{Bibliografía}

Bunn, D. (2009). Tajando las ideas: literatura y alimento. Omnibus. 27. Recuperado de http:// www.omni-bus.com/n27/bunn.html

Calvillo Jurado, M. (s.f.). Introducción a las relaciones entre cocina y literatura (un artículo para abrir boca). Recuperado de https://cocinayliteratura.wikispaces.com/Introducció $\mathrm{n}+\mathrm{a}+\mathrm{las}+$ relaciones+entre+Cocina+y+Literatura

Fernández Guardia, R. (1995). Carta No. 2 (24 de junio de 1894). En A. Segura Montero (Ed.). La polémica (1894-1902): El nacionalismo en la literatura. (pp. 21-25). San José: EUNED

Fernández Guardia, R. (2004a). Cuentos ticos. San José: EUNED.

Fernández Guardia, R. (2004b). Hojarasca. San José: EUNED.

Gagini, C. (1919). Diccionario de costarriqueñismos. San José: Imprenta Nacional.

Gagini, C. (1995). Carta No 1 (28 de mayo de 1894). En A. Segura Montero (Ed.). La polémica (1894-1902): El nacionalismo en literatura. (pp. 19-20). San José: EUNED.

Lotman, I. (1996). La semiosfera I. Semiótica de la cultura y del texto. Madrid: Ediciones Cátedra.

Quesada Soto, Á. (1995). La formación narrativa nacional costarricense (1890-1910). Enfoque histórico. San José: Editorial de la Universidad de Costa Rica.

Sanabria Marchena, J. (2015). El nacimiento de la corporaciones azucareras en Guanacaste, 1890-1970. Diálogos, 16 (2), 83-119.

Segura Montero, A. (Ed.). (1995). La polémica (1894-1902): El nacionalismo en literatura. San José: EUNED.

Tomashevsky, B. (1978). Temática. Teoría de la literatura de los formalistas rusos. En T. Todorov (Ed.) (pp. 199-232). México: Siglo XXI Editores.

Todorov, T. (2007). La conquista de América. El problema del otro. Madrid: Siglo XXI Editores. 
